\title{
Annealing Effect on Photovoltaic Performance of CdSe Quantum-Dots-Sensitized TiO 2 Nanorod Solar Cells
}

\author{
Yitan Li, ${ }^{1}$ Lin Wei, ${ }^{2}$ Ruizi Zhang, ${ }^{1}$ Yanxue Chen, ${ }^{1}$ and Jun Jiao ${ }^{3}$ \\ ${ }^{1}$ School of Physics and State Key Laboratory of Crystal Materials, Shandong University, Jinan 250100, China \\ ${ }^{2}$ School of Information Science and Engineering, Shandong University, Jinan 250100, China \\ ${ }^{3}$ Department of Physics, Portland State University, P.O. Box 751, Portland, OR 97207-0751, USA \\ Correspondence should be addressed to Yanxue Chen, cyx@sdu.edu.cn
}

Received 4 August 2012; Revised 22 October 2012; Accepted 24 October 2012

Academic Editor: Jian Wei

Copyright (C) 2012 Yitan Li et al. This is an open access article distributed under the Creative Commons Attribution License, which permits unrestricted use, distribution, and reproduction in any medium, provided the original work is properly cited.

Large area rutile $\mathrm{TiO}_{2}$ nanorod arrays were grown on $\mathrm{F}: \mathrm{SnO}_{2}$ (FTO) conductive glass using a hydrothermal method at low temperature. CdSe quantum dots (QDs) were deposited onto single-crystalline $\mathrm{TiO}_{2}$ nanorod arrays by a chemical bath deposition (CBD) method to make a photoelectrode. The solar cell was assembled using a CdSe- $\mathrm{TiO}_{2}$ nanostructure as the photoanode and polysulfide solution as the electrolyte. The annealing effect on optical and photovoltaic properties of CdSe quantum-dotssensitized $\mathrm{TiO}_{2}$ nanorod solar cells was studied systematically. A significant change of the morphology and a regular red shift of band gap of CdSe nanoparticles were observed after annealing treatment. At the same time, an improved photovoltaic performance was obtained for quantum-dots-sensitized solar cell using the annealed $\mathrm{CdSe}-\mathrm{TiO}_{2}$ nanostructure electrode. The power conversion efficiency improved from $0.59 \%$ to $1.45 \%$ as a consequence of the annealing effect. This improvement can be explained by considering the changes in the morphology, the crystalline quality, and the optical properties caused by annealing treatment.

\section{Introduction}

At present, technologies to utilize solar energy have attracted world-wide attention. Although the solar cells based on monocrystalline Si could provide ample power, their relatively high cost has impaired the research and development of new photovoltaic (PV) systems. Many new PV systems have been introduced including dye-sensitized solar cell [13], organic solar cells [4], and multijunction solar cells [5]. As a promising alternative to silicon-based solar cells, dyesensitized solar cells (DSSCs) have played a promising role in the development of renewable energy. In the laboratory, DSSCs can reach light-to-electric conversion efficiencies of up to $11 \%$ [6]. Although the results reported recently are very impressive, the use of expensive dye to sensitize the solar cell is still not feasible for practical applications. Therefore, it is critical to tailor the materials to be not only cost-effective but also long lasting.
Considering the high cost and low stability of organic dyes, using nanosized narrowband gap semiconductor materials as sensitizers in place of the molecular dyes in DSSCs has been put forward as an efficient and promising alternative. Inorganic semiconductors have several advantages over conventional dyes. (i) The band gap of semiconductor quantum dots (QDs) can be tuned by size to match the solar spectrum. (ii) Their large intrinsic dipole moments can lead to rapid charge separation and a large extinction coefficient, which is known to reduce the dark current and increase the overall efficiency. (iii) In addition, semiconductor QD sensitizers provide new chances to utilize hot electrons or generate multiple charge carriers with a single photon. Hence, nanosized narrowband gap semiconductors are ideal candidates for the optimization of a solar cell for improved performance.

Recently, various nanosized semiconductors including CdS [7], CdSe [8], CdTe [9], $\mathrm{Sb}_{2} \mathrm{~S}_{3}[10,11]$, and $\mathrm{Bi}_{2} \mathrm{~S}_{3}$ 
[12] have been studied for photocatalyst and solar cell applications. Among these sensitizers, CdSe has shown much promise as an impressive sensitizer due to its reasonable band gap of about $1.70 \mathrm{eV}$, which has a strong absorption of the solar spectrum. The use of CdSe quantum dots, which may produce more than one electron-hole pair per single absorbed photon (also known as multiple exciton generation (MEG)), is a promising solution to enhance power conversion efficiency. Furthermore, the creation of a type-II heterojunction by growing CdSe QDs on the $\mathrm{TiO}_{2}$ surface greatly enhances charge separation. All these effects are known to increase the exciton concentration, quantum yield, and lifetime of hot electrons and therefore, the performance of QD-sensitized solar cells.

To date, $\mathrm{CdSe}-\mathrm{TiO}_{2}$-nanostructured solar cells have been reported by several groups [13-16]. While most of the reported work was conducted on polycrystalline $\mathrm{TiO}_{2}$, little work has been done on the single-crystalline $\mathrm{TiO}_{2}$ nanorod arrays. Compared with polycrystalline $\mathrm{TiO}_{2}$, singlecrystalline $\mathrm{TiO}_{2}$ nanorods grown directly on transparent conductive oxide (TCO) electrodes provide a perfect solution by avoiding the particle-to-particle hopping that occurs in polycrystalline films, thereby increasing the photocurrent efficiency.

In this paper, we combine CdSe semiconductor quantum dots and single-crystalline rutile $\mathrm{TiO}_{2}$ nanorod arrays to produce a practical quantum-dot-sensitized solar cell. A low-temperature hydrothermal technique was used to grow ordered $\mathrm{TiO}_{2}$ nanorod arrays directly on fluorine-doped tin oxide (FTO) glass, and CdSe nanoparticles were deposited using a CBD method. Postpreparation annealing was conducted to improve the solar cell performance. After annealing, apparent changes in morphology, optical and photovoltaic properties were observed. The photoconversion efficiency of the quantum-dots-sensitized solar cell assembled using a $\mathrm{CdSe}-\mathrm{TiO}_{2}$ nanostructure annealed at $400^{\circ} \mathrm{C}$ for 30 min showed an increase of $146 \%$ compared with that based on as-grown $\mathrm{CdSe}-\mathrm{TiO}_{2}$ nanostructure.

\section{Experimental}

2.1. Growth of Single-Crystalline Rutile $\mathrm{TiO}_{2}$ Nanorods by Hydrothermal Process. Ordered $\mathrm{TiO}_{2}$ nanostructures with different morphologies, such as nanowires [17], nanotubes [18], and nanoparticles [19], have been obtained by different groups using hard-template methods. Alternative wet-chemical techniques for crystalline $\mathrm{TiO}_{2}$ growth and morphology control are also an interesting and promising subject. It is known that in wet-chemical techniques, the particle size, morphology, and structure can be easily controlled by adjusting preparation parameters. In this study, single crystal rutile $\mathrm{TiO}_{2}$ nanorod arrays were directly grown on fluorine-doped-tin-oxide- (FTO-) coated glass using the following hydrothermal method. $50 \mathrm{~mL}$ of deionized water was mixed with $40 \mathrm{~mL}$ of concentrated hydrochloric acid ( $\mathrm{HCl}, 36-38 \%$ by weight, Sinopharm). After stirring at ambient temperature for $5 \mathrm{~min}, 400 \mu \mathrm{L}$ of titanium tetrachloride $\left(\mathrm{TiCl}_{4}, 99.9 \%\right.$, Aladdin) was added to the mixture.
The mixture was injected into a stainless steel autoclave with a Teflon container cartridge. The FTO substrates were ultrasonically cleaned for $10 \mathrm{~min}$ in a mixed solution of deionized water, acetone, and 2-propanol with volume ratios of $1: 1: 1$ and then were placed at an angle against the Teflon container wall with the conducting side facing down. The hydrothermal synthesis was conducted at $180^{\circ} \mathrm{C}$ for $2 \mathrm{~h}$. After synthesis, the autoclave was cooled to room temperature under flowing water, and the FTO substrates were taken out, washed extensively with deionized water, and dried in the open air.

2.2. Deposition of CdSe Nanoparticles with Chemical Bath Deposition (CBD) Method and Annealing Treatment. In a typical CBD cycle, the $\mathrm{F}: \mathrm{SnO}_{2}$ conductive glass, pregrown with $\mathrm{TiO}_{2}$ nanorod arrays, was dipped into the $0.2 \mathrm{M}$ cadmium chloride $\left(\mathrm{CdCl}_{2}\right)$ solution for 5 minutes, rinsed in water, then dipped into the $0.1 \mathrm{M}$ sodium selenosulphate solution (obtained by constantly stirring the mixed solution of selenium powder and sodium sulphite for $6 \mathrm{~h}$ at $50^{\circ} \mathrm{C}$ ) for another 5 minutes at $80^{\circ} \mathrm{C}$, and rinsed in water. This entire CBD process was repeated from 5 to 9 cycles to achieve the desired thickness of CdSe nanoparticles layer. To investigate the annealing effect on the optical and structural properties of synthesized $\mathrm{CdSe}-\mathrm{TiO}_{2}$ nanostructures, annealing treatments were carried out in air at varied temperatures from $100^{\circ} \mathrm{C}$ to $400^{\circ} \mathrm{C}$ for $30 \mathrm{~min}$ using a tube furnace.

2.3. Characterization. A field emission scanning electron microscope (SEM, S-4800, Hitachi) and a transmission electron microscope (TEM, JEOL JEM-2100) were used to characterize the morphology and internal structures of the samples. The crystal structure of the $\mathrm{CdSe}-\mathrm{TiO}_{2}$ samples was examined by X-ray diffraction (XD-3, PG Instruments Ltd.) with $\mathrm{Cu} K \alpha$ radiation $(\lambda=0.154 \mathrm{~nm})$ at a scan rate of $2^{\circ}$ per min. X-ray tube voltage and current were set at $40 \mathrm{kV}$ and $35 \mathrm{~mA}$, respectively. The optical absorption spectra were obtained using a UV-visible spectrometer (TU-1900, PG Instruments, Ltd.).

2.4. J-V Measurements. Solar cells were assembled using $\mathrm{CdSe}-\mathrm{TiO}_{2}$ nanostructures as the photoanode. Pt counter electrodes were prepared by depositing $20 \mathrm{~nm}$ thick Pt film on FTO glass using magnetron sputtering. A $60 \mu \mathrm{m}$ thick sealing material (SX-1170-60, Solaronix SA) with a $2.5 \times$ $2.5 \mathrm{~mm}$ aperture was pasted onto the Pt counter electrodes. The Pt counter electrode and the $\mathrm{CdSe}-\mathrm{TiO}_{2}$ photoelectrode were sandwiched and sealed with the conductive sides facing inward. A polysulfide electrolyte was injected into the space between the two electrodes. The polysulfide electrolyte was composed of $1 \mathrm{M}$ sulfur, $1 \mathrm{M} \mathrm{Na}_{2} \mathrm{~S}$, and $0.1 \mathrm{M} \mathrm{NaOH}$, which were dissolved in methanol/water $(7: 3, \mathrm{v} / \mathrm{v})$ and stirred at $80^{\circ} \mathrm{C}$ for $2 \mathrm{~h}$.

A solar simulator (Model 94022A, Newport) with an AM1.5 filter was used to illuminate the working solar cell at light intensity of 1 sun illumination $\left(100 \mathrm{~mW} / \mathrm{cm}^{2}\right)$. A sourcemeter (2400, Keithley) was used for electrical characterization during the measurements. The measurements 


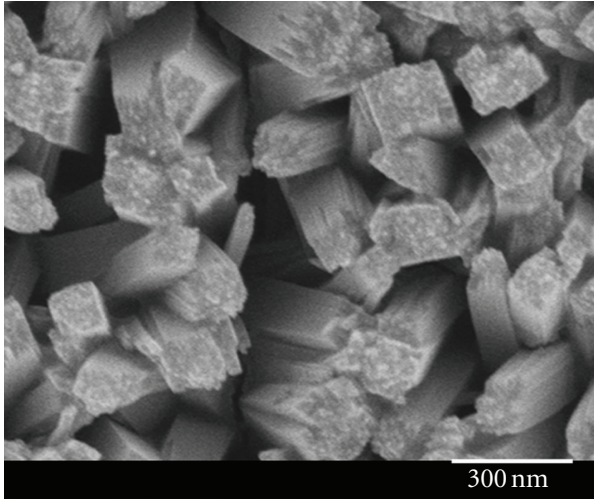

(a)

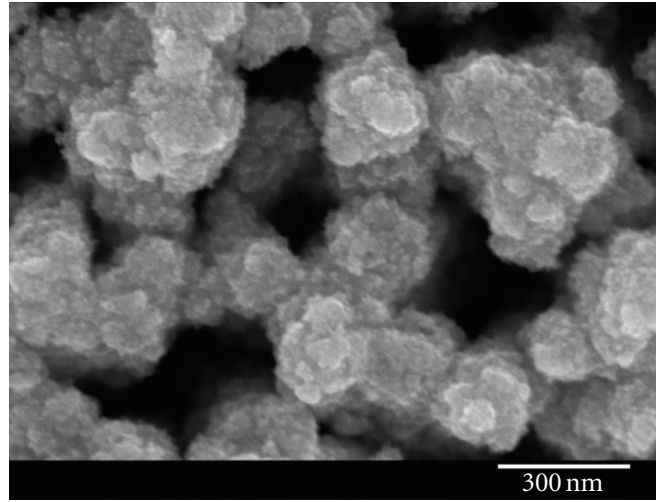

(b)

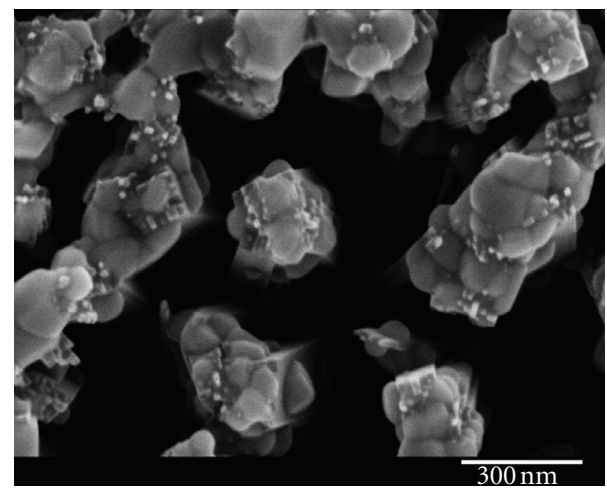

(c)

FIGURE 1: Top view SEM images of the bare $\mathrm{TiO}_{2}$ nanorod (a), the $\mathrm{CdSe}-\mathrm{TiO}_{2}$ nanostructure after $7 \mathrm{CBD}$ cycles (b), and the sample with 7 $\mathrm{CBD}$ cycles annealed at $400^{\circ} \mathrm{C}$ for 30 minutes (c).

were carried out with respect to a calibrated OSI standard silicon solar photodiode.

\section{Results and Discussion}

Field emission scanning electron microscopy (FESEM) images show a typical morphology of the rutile $\mathrm{TiO}_{2}$ nanorod arrays in Figure 1(a), confirming that the entire surface of the FTO-coated glass substrate was uniformly covered with ordered $\mathrm{TiO}_{2}$ nanorods. The nanorods are typically $100-150 \mathrm{~nm}$ in diameter and are tetragonal in shape with square top facets consisting of many small grids. The density of nanorods is 20 nanorods $/ \mu \mathrm{m}^{2}$ with suitable space for deposition of CdSe nanoparticles. The CdSe QDs deposited onto $\mathrm{TiO}_{2}$ nanorods with different CBD cycles were also characterized by FESEM. The SEM results (not shown here) suggest that as the number of CBD cycles increased from 5 to 7 and then to 9, the thickness of the CdSe nanoparticles increased correspondingly. A thicker CdSe nanoparticles layer is beneficial for stronger sunlight absorption, but will cause severe recombination of photo-induced carriers at the same time. Hence, an optimal thickness should be determined to achieve a higher power conversion efficiency. In our experiment, the best photovoltaic performance was observed in the $\mathrm{CdSe}-\mathrm{TiO}_{2}$ photoelectrode deposited with 7 CBD cycles. Therefore, in the following research process we are focused on this $\mathrm{CdSe}-\mathrm{TiO}_{2}$ nanostructure with 7 deposition cycles to study the annealing effect on optical and photovoltaic properties. A close look at the $\mathrm{CdSe}-\mathrm{TiO}_{2}$ nanostructure with 7 successive deposition cycles is shown in Figure 1(b). A uniform porous CdSe shell composed of small nanoparticles was formed on the $\mathrm{TiO}_{2}$ nanorod surface. Figure 1(c) showed the morphology of this CdSe$\mathrm{TiO}_{2}$ nanostructure after annealing at $400^{\circ} \mathrm{C}$ for 30 minutes. Compared with Figure 1(b), a significant change in the morphology was observed. After annealing, the porous CdSe layer transformed into larger CdSe particles with size of about 100 to $150 \mathrm{~nm}$. Also, as shown in Figure 1(c), this annealing treatment enabled a much close contact btween CdSe particle and the $\mathrm{TiO}_{2}$ nanorod surface. This firm connection is beneficial to the charge separation and will improve the overall properties of the sensitized solar cells.

The detailed microscopic structure of the CdSe nanoparticles before and after annealing was further investigated by a high-resolution TEM. For the as-deposited sample only a blurred HRTEM image (Figure 2(a)) was obtained, which indicates that the CdSe layer is polycrystalline with a poor crystallization. Further characterization suggests that the CdSe shell consists of nanoparticles with an average diameter of approximately 5-10 $\mathrm{nm}$, which is coincident with the SEM measurement above. The HRTEM image of the annealed $\mathrm{CdSe}-\mathrm{TiO}_{2}$ nanostructure is presented in Figure 2(b). 


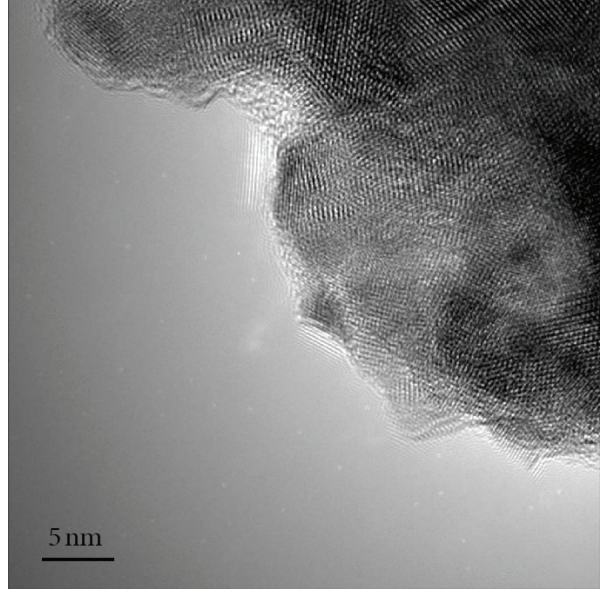

(a)

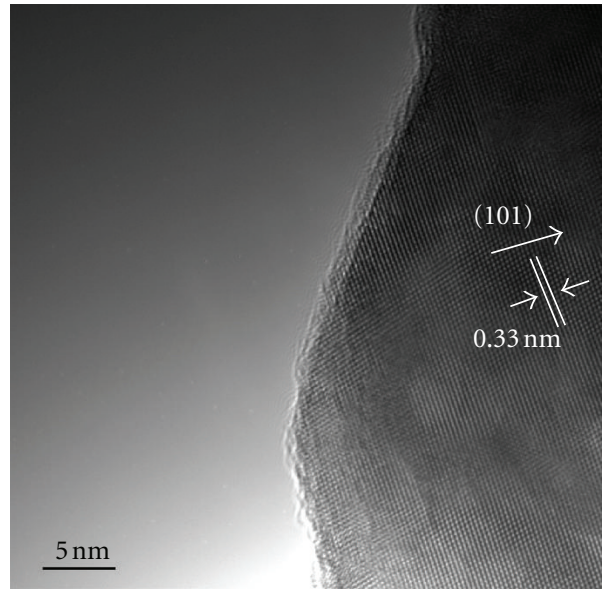

(b)

Figure 2: HRTEM images of CdSe nanoparticles deposited on $\mathrm{TiO}_{2}$ nanorod arrays before (a) and after (b) annealing treatment.

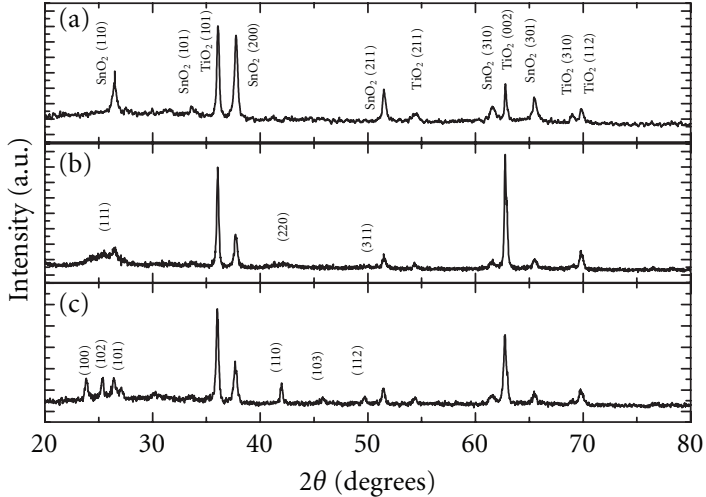

FIgURE 3: XRD patterns of (a) the $\mathrm{TiO}_{2}$ bare nanorod array, (b) the as-synthesized $\mathrm{CdSe}-\mathrm{TiO}_{2}$ nanorod array electrode, and (c) the $\mathrm{CdSe}-\mathrm{TiO}_{2}$ nanorod array electrode annealed at $400^{\circ} \mathrm{C}$ for $30 \mathrm{~min}$. All the peaks from $\mathrm{SnO}_{2}$ and $\mathrm{TiO}_{2}$ are indexed in (a), and those from CdSe nanoparticles are indexed in (b) and (c).

The clear lattice fringes in the HRTEM image indicate that the CdSe particle has a high degree of crystallinity. The lattice spacing is measured to be approximately $0.33 \mathrm{~nm}$, which agrees well with the spacing of the (101) planes of the wurtzite CdSe. The high interior crystal quality of the CdSe nanoparticles is conducive to reduce the recombination of the excited electron-hole pairs and increase the photocurrent of the solar cells.

X-ray diffraction (XRD) patterns of the bare $\mathrm{TiO}_{2}$ nanorod array, the as-synthesized $\mathrm{CdSe}-\mathrm{TiO}_{2}$ nanostructure, and the annealed nanostructure are shown in Figure 3. Note in Figure 3(a) that the $\mathrm{TiO}_{2}$ nanorod arrays grown on the FTO-coated glass substrates have a tetragonal rutile structure (JCPDS no. 02-0494), which could be attributed to the small lattice mismatch between FTO and rutile. The as-synthesized $\mathrm{CdSe}-\mathrm{TiO}_{2}$ nanostructure exhibits weak diffraction peaks at $2 \theta=25.3^{\circ}, 42.0^{\circ}$, and $49.8^{\circ}$, corresponding to the (111), (220), and (311) planes of metastable cubic (sphalerite)

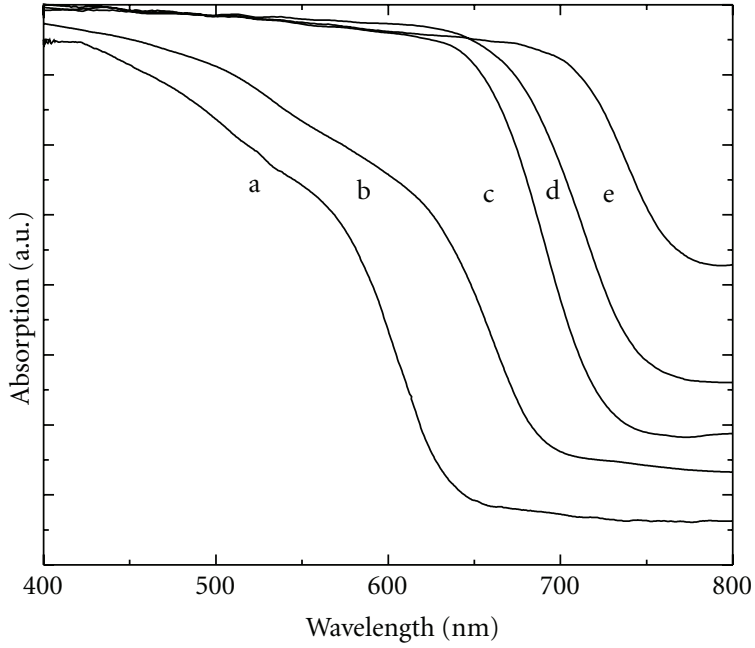
(a) As-synthetized
(b) Annealed $100^{\circ} \mathrm{C}$
(c) Annealed $200^{\circ} \mathrm{C}$
(d) Annealed $300^{\circ} \mathrm{C}$
(e) Annealed $400^{\circ} \mathrm{C}$

FIgUre 4: Optical absorption spectra of $\mathrm{CdSe}-\mathrm{TiO}_{2}$ nanostructure samples before (a) and after annealing at $100^{\circ} \mathrm{C}$ (b), $200^{\circ} \mathrm{C}$ (c), $300^{\circ} \mathrm{C}(\mathrm{d})$, and $400^{\circ} \mathrm{C}(\mathrm{e})$.

CdSe with the lattice constant $\mathrm{a}=0.609 \mathrm{~nm}$ (JCPDS no. 19-0191). After being annealed at $400^{\circ} \mathrm{C}$, diffraction peaks could be indexed as the (100), (102), (101), (110), (103), and (112) planes of wurtzite hexagonal phase (JCPDS no. 08-0459). Compared with Figure 3(b), it is obvious that for the annealed samples, the diffraction peaks became sharper and the full width at half maximum (FWHM) decreased. This was due to the improvement of the crystalline and the increase in particle size during the annealing process.

The optical absorption spectra of $\mathrm{CdSe}-\mathrm{TiO}_{2}$ nanostructure samples are shown in Figure 4. An optical band gap of $2.04 \mathrm{eV}$ is estimated for the as-synthesized CdSe nanoparticles from the absorption spectra, which are much 


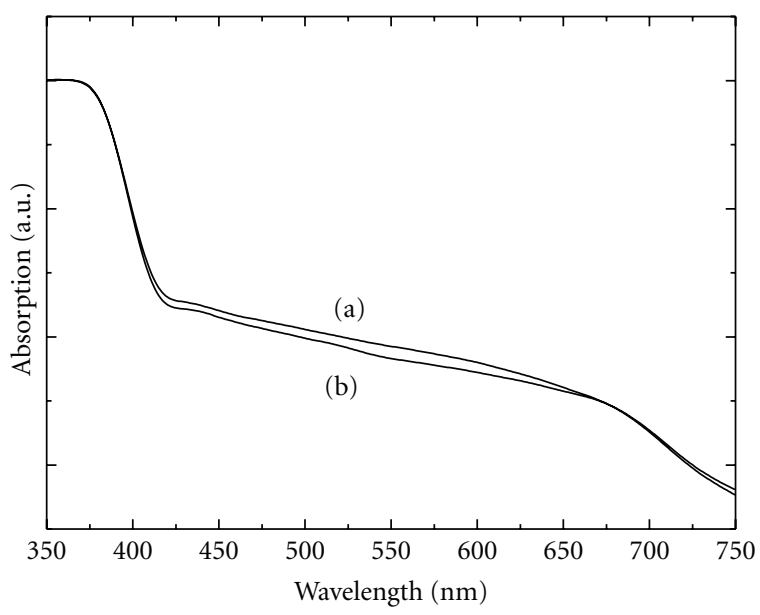

(a) As-synthetized

(b) Annealed under $400^{\circ} \mathrm{C}$

Figure 5: Optical absorption spectra of nanorod arrays with and without annealing treatment.

wider than that of bulk wurtzite CdSe. After annealing at $100^{\circ} \mathrm{C}, 200^{\circ} \mathrm{C}, 300^{\circ} \mathrm{C}$, and $400^{\circ} \mathrm{C}$ for $30 \mathrm{~min}$, respectively, the band gap of CdSe nanoparticles was red-shifted to $1.88 \mathrm{eV}$ $(660 \mathrm{~nm}), 1.80 \mathrm{eV}(690 \mathrm{~nm}), 1.74 \mathrm{eV}(714 \mathrm{~nm})$, and $1.68 \mathrm{eV}$ $(736 \mathrm{~nm})$ accordingly (Figures $4(\mathrm{~b})-4(\mathrm{e}))$. The annealed $\mathrm{CdSe}-\mathrm{TiO}_{2}$ nanostructures show an enhanced absorption in the visible range, which is very important for solar cell application and will result in higher power conversion efficiency. As shown by the XRD patterns, SEM images and HRTEM images, this red shift in the annealed samples could be explained by the annealing-induced phase transformation (from cubic to hexagonal) at the elevated temperatures as well as the increase in particle size [20]. The annealing effect on the optical absorption spectra of bare $\mathrm{TiO}_{2}$ nanorod arrays was also studied. As shown in Figure 5, no obvious difference was found between the samples with and without annealing treatment. This result suggests that although annealing changes the morphology and crystallinity of CdSe nanoparticles, it does not have significant effect on the optical property of the $\mathrm{TiO}_{2}$ nanorod arrays.

Figure 6 shows the photocurrent-voltage (I-V) performance of the quantum-dots-sensitized solar cells assembled using $\mathrm{CdSe}-\mathrm{TiO}_{2}$ nanostructures annealed under different temperatures. The I-V curves of the QDSSC were measured under one sun illumination (AM1.5, $\left.100 \mathrm{~mW} / \mathrm{cm}^{2}\right)$. An open-circuit voltage ( $\mathrm{Voc}$ ) of $0.33 \mathrm{~V}$, a short-circuit current density (Jsc) of $7.8 \mathrm{~mA} / \mathrm{cm}^{2}$, and an overall efficiency of $0.59 \%$ were observed for QDSSC based on the as-grown $\mathrm{CdSe}-\mathrm{TiO}_{2}$ nanostructure. As the annealing temperature increased, the open-circuit voltage (Voc) was improved from $0.33 \mathrm{~V}$ to $0.38 \mathrm{~V}$, and the short-circuit current density (Jsc) was increased from $7.7 \mathrm{~mA} / \mathrm{cm}^{2}$ to $12.5 \mathrm{~mA} / \mathrm{cm}^{2}$. An overall efficiency of $1.45 \%$ was observed for QDSSC based on $\mathrm{CdSe}-\mathrm{TiO}_{2}$ nanostructures annealed at $400^{\circ} \mathrm{C}$, indicating an increase of up to $146 \%$ compared with that of the assynthesized one.

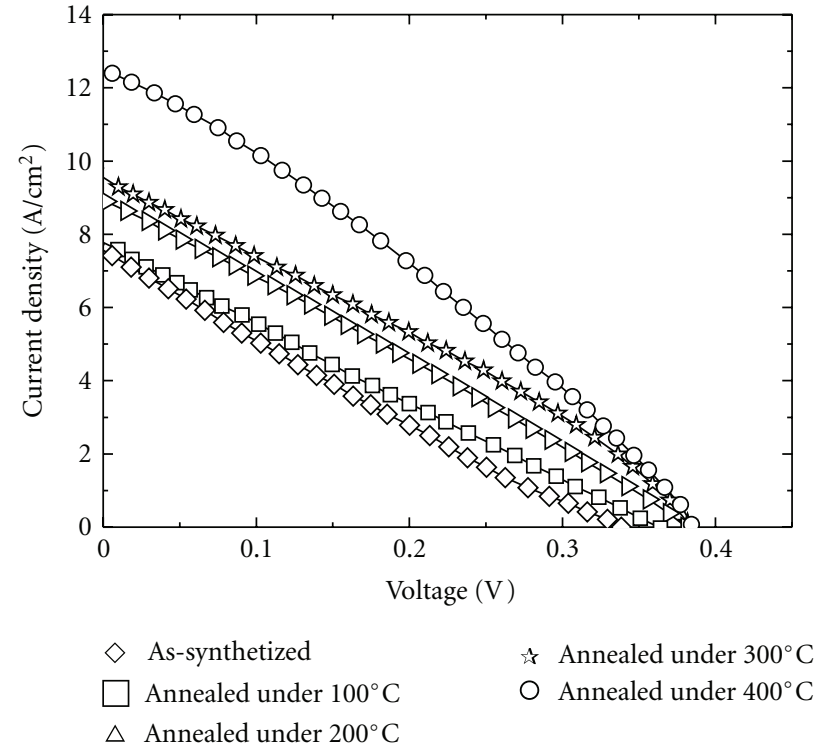

Figure 6: I-V curves for the solar cells assembled using $\mathrm{CdSe}-\mathrm{TiO}_{2}$ nanostructures annealed under different temperatures.

This significant improvement of the photovoltaic performance obtained for QDSSC based on annealed CdSe- $\mathrm{TiO}_{2}$ nanostructure can be ascribed to the following reasons. (i) As confirmed by the absorption spectra presented in Figure 4, an enhanced absorption of sunlight caused by the red shift of the band gap will result in an enhanced current density. (ii) Increase of CdSe grain size by annealing will reduce the particle-to-particle hopping of the photo-induced carrier. This hopping may occur in an as-grown nanostructure with a CdSe layer composed of CdSe nanoparticles. (iii) Improvement of crystal quality of the CdSe nanoparticles by annealing treatment will decrease the internal defects, which can reduce the recombination of photoexcited carriers and result in a higher power conversion efficiency. (iv) Good contact between the CdSe quantum dots and the $\mathrm{TiO}_{2}$ nanorod is formed as a result of high-temperature annealing. Such a superior interface between $\mathrm{TiO}_{2}$ and QDs can inhibit the interfacial recombination of the injected electrons from $\mathrm{TiO}_{2}$ to the electrolyte, which is also responsible for its higher efficiency.

This study opens the possibility of using a 3D nanostructure material with a facile hydrothermal method for QDSSC studies. In present work, the low photoelectric efficiency may be caused by the low transport efficiency of the $S / S^{-2}$ redox couple. By applying more efficient redox couple electrolyte, higher cell efficiency could be achieved.

\section{Conclusions}

Using a facile hydrothermal method, the single-crystalline $\mathrm{TiO}_{2}$ nanorod arrays were successfully grown on fluorinedoped tin oxide (FTO) glass. Then the densely distributed CdSe nanoparticles were deposited on $\mathrm{TiO}_{2}$ nanorod arrays using a chemical bath deposition (CBD) method. Annealing 
was conducted to improve the properties of the CdSe$\mathrm{TiO}_{2}$ nanostructure. Greatly improved crystallinity of CdSe nanoparticles and obvious enhancement in visible light absorption were observed for the annealed samples. Significant improvement of the photovoltaic performance for QDSSC based on the annealed $\mathrm{CdSe}-\mathrm{TiO}_{2}$ nanostructure was obtained. Compared with QDSSC based on as-deposited $\mathrm{CdSe}-\mathrm{TiO}_{2}$ nanostructures, an increase of up to $146 \%$ in power conversion efficiency was achieved for QDSSCs using the annealed $\mathrm{CdSe}-\mathrm{TiO}_{2}$ photoanode.

\section{Acknowledgments}

This work was supported by the State Key Research Development Program of China (2010CB833103), the National Natural Science Foundation of China (60976073), the National Found for Fostering Talents of Basic Science (J1103212), and the Foundation for Outstanding Young Scientist in Shandong Province (BS2010CL036). J. Jiao thanks the financial support from the Oregon Nanoscience Microtechnologies Institute (ONAMI) and the National Science Foundation.

\section{References}

[1] B. O’Regan and M. Grätzel, "A low-cost, high-efficiency solar cell based on dye-sensitized colloidal $\mathrm{TiO}_{2}$ films," Nature, vol. 353, no. 6346, pp. 737-740, 1991.

[2] M. Grätzel, "Photoelectrochemical cells," Nature, vol. 414, no. 6861, pp. 338-344, 2001.

[3] H. S. Chen, C. Su, J. L. Chen, T. Y. Yang, N. M. Hsu, and W. R. Li, "Preparation and characterization of pure rutile $\mathrm{TiO}_{2}$ nanoparticles for photocatalytic study and thin films for dye-sensitized solar cells," Journal of Nanomaterials, vol. 2011, Article ID 869618, 8 pages, 2011.

[4] F. A. de Castro, F. Nüesch, C. Walder, and R. Hany, "Challenges found when patterning semiconducting polymers with electric fields for organic solar cell applications," Journal of Nanomaterials, vol. 2012, Article ID 478296, 6 pages, 2012.

[5] M. Yamaguchi, "Multi-junction solar cells and novel structures for solar cell applications," Physica E, vol. 14, no. 1-2, pp. 84-90, 2002.

[6] Y. Chiba, A. Islam, Y. Watanabe, R. Komiya, N. Koide, and L. Han, "Dye-sensitized solar cells with conversion efficiency of 11.1\%," Japanese Journal of Applied Physics, vol. 45, no. 24-28, pp. L638-L640, 2006.

[7] C. Wang, Z. Jiang, L. Wei et al., "Photosensitization of $\mathrm{TiO}_{2}$ nanorods with CdS quantum dots for photovoltaic applications: a wet-chemical approach," Nano Energy, vol. 1, no. 3, pp. 440-447, 2012.

[8] U. Farva and C. Park, "Colloidal synthesis and air-annealing of CdSe nanorods for the applications in hybrid bulk heterojunction solar cells," Materials Letters, vol. 64, no. 13, pp. 1415-1417, 2010.

[9] A. Morales-Acevedo, “Thin film CdS/CdTe solar cells: research perspectives," Solar Energy, vol. 80, no. 6, pp. 675-681, 2006.

[10] Y. Itzhaik, O. Niitsoo, M. Page, and G. Hodes, " $\mathrm{Sb}_{2} \mathrm{~S}_{3}$ sensitized nanoporous $\mathrm{TiO}_{2}$ solar cells," Journal of Physical Chemistry C, vol. 113, no. 11, pp. 4254-4256, 2009.

[11] M. Sun, G. Chen, Y. Zhang, Q. Wei, Z. Ma, and B. Du, "Efficient degradation of azo dyes over $\mathrm{Sb}_{2} \mathrm{~S}_{3} / \mathrm{TiO}_{2}$ heterojunction under visible light irradiation," Industrial \& Engineering Chemistry Research, vol. 51, no. 7, pp. 2897-2903, 2012.
[12] L. M. Peter, K. G. U. Wijayantha, D. J. Riley, and J. P. Waggett, "Band-edge tuning in self-assembled layers of $\mathrm{Bi}_{2} \mathrm{~S}_{3}$ nanoparticles used to photosensitize nanocrystalline $\mathrm{TiO}_{2}$," Journal of Physical Chemistry B, vol. 107, no. 33, pp. 8378-8381, 2003.

[13] I. Robel, V. Subramanian, M. Kuno, and P. V. Kamat, "Quantum dot solar cells. Harvesting light energy with CdSe nanocrystals molecularly linked to mesoscopic $\mathrm{TiO}_{2}$ films," Journal of the American Chemical Society, vol. 128, no. 7, pp. 2385-2393, 2006.

[14] J. Y. Kim, S. B. Choi, J. H. Noh et al., "Synthesis of CdSe-TiO 2 nanocomposites and their applications to $\mathrm{TiO}_{2}$ sensitized solar cells," Langmuir, vol. 25, no. 9, pp. 5348-5351, 2009.

[15] L. Liu, J. Hensel, R. C. Fitzmorris, Y. Li, and J. Z. Zhang, "Preparation and photoelectrochemical properties of $\mathrm{CdSe} / \mathrm{TiO}_{2}$ hybrid mesoporous structures," Journal of Physical Chemistry Letters, vol. 1, no. 1, pp. 155-160, 2010.

[16] L. Yang, S. Luo, R. Liu et al., "Fabrication of cdse nanoparticles sensitized long $\mathrm{TiO}_{2}$ nanotube arrays for photocatalytic degradation of anthracene-9-carbonxylic acid under green monochromatic light," Journal of Physical Chemistry C, vol. 114, no. 11, pp. 4783-4789, 2010.

[17] Z. Zhou, J. Fan, X. Wang, W. Zhou, Z. Du, and S. Wu, "Effect of highly ordered single-crystalline $\mathrm{TiO}_{2}$ nanowire length on the photovoltaic performance of dye-sensitized solar cells," ACS Applied Materials \& Interfaces, vol. 3, no. 11, pp. 43494353, 2011.

[18] J. Wang and Z. Lin, "Dye-sensitized $\mathrm{TiO}_{2}$ nanotube solar cells with markedly enhanced performance via rational surface engineering," Chemistry of Materials, vol. 22, no. 2, pp. 579$584,2010$.

[19] P. Wang, A. Abrusci, H. M. P. Wong, M. Svensson, M. R. Andersson, and N. C. Greenham, "Photoinduced charge transfer and efficient solar energy conversion in a blend of a red polyfluorene copolymer with CdSe nanoparticles," Nano Letters, vol. 6, no. 8, pp. 1789-1793, 2006.

[20] A. Kongkanand, K. Tvrdy, K. Takechi, M. Kuno, and P. V. Kamat, "Quantum dot solar cells. Tuning photoresponse through size and shape control of $\mathrm{CdSe}-\mathrm{TiO}_{2}$ architecture," Journal of the American Chemical Society, vol. 130, no. 12, pp. 4007-4015, 2008. 

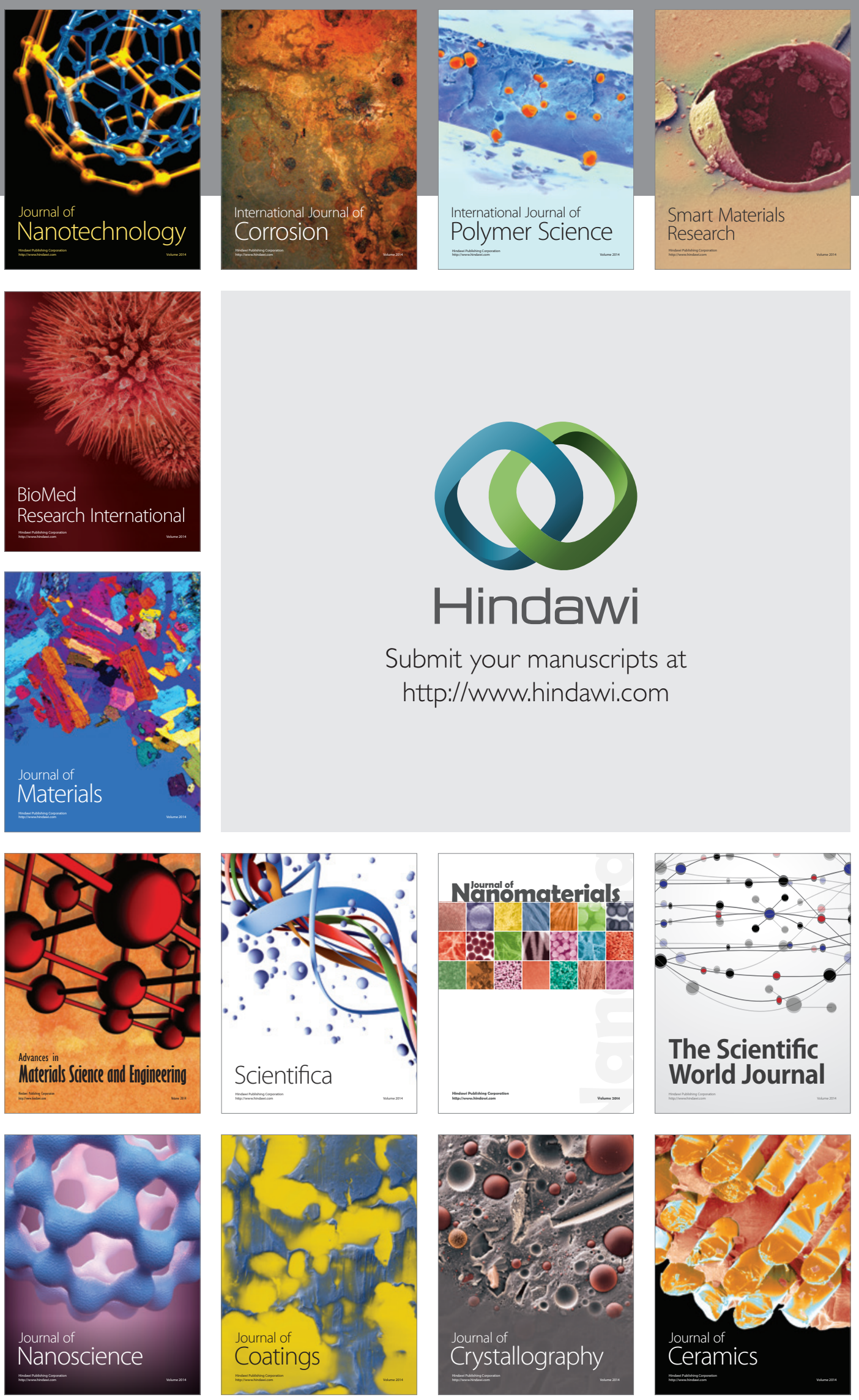

The Scientific World Journal

Submit your manuscripts at

http://www.hindawi.com

\section{World Journal}

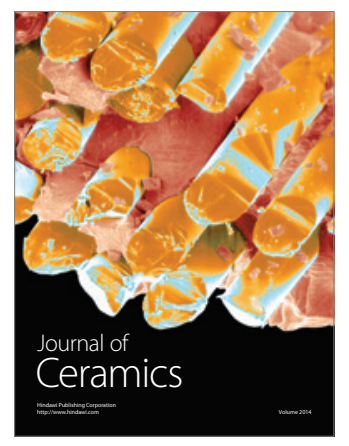

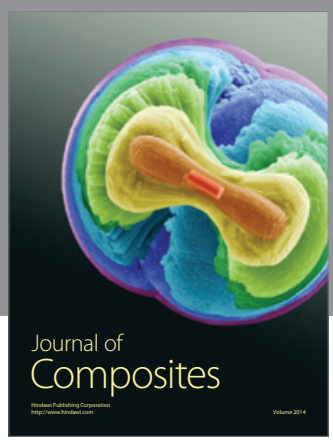
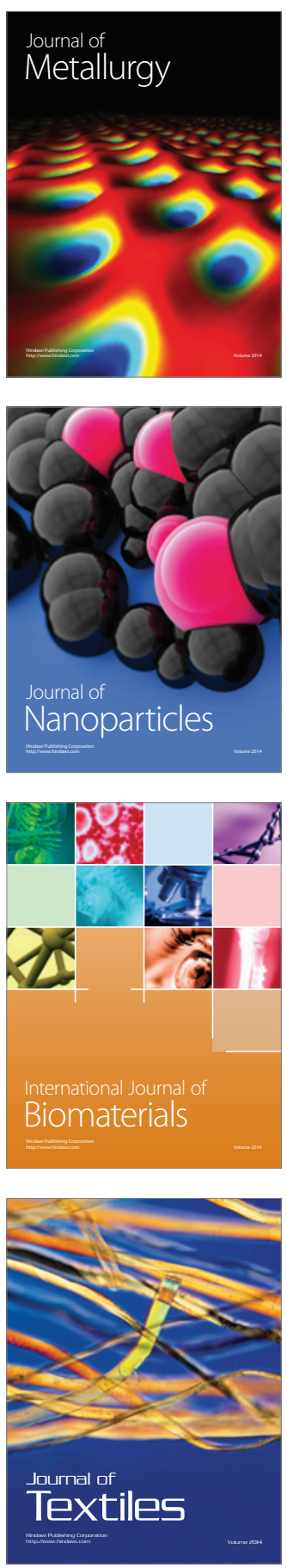